\title{
Scrotal abscess as a complication of perforated appendicitis: A case report and review of the literature Mohammad M Saleem
}

Address: The Department of Pediatric Surgery, Jordan University Hospital, University of Jordan, Amman, Jordan

Email: Mohammad M Saleem - mohomari@hotmail.com

Published: 19 September 2008

Cases Journal 2008, I:165 doi:10.1186/1757-1626-1-165

This article is available from: http://www.casesjournal.com/content/I/I//65

(C) 2008 Saleem; licensee BioMed Central Ltd.

This is an Open Access article distributed under the terms of the Creative Commons Attribution License (http://creativecommons.org/licenses/by/2.0), which permits unrestricted use, distribution, and reproduction in any medium, provided the original work is properly cited.
Received: 29 July 2008

Accepted: 19 September 2008

\begin{abstract}
Introduction: Abscess formation following appendectomy is well known, especially when complicated by perforation. Infectious complications are the most common. Intraabdominal abscess formation, Pelvic abscess and wound infection are the most common sites of infection. Scrotal abscess following acute perforated appendicitis is very rare.

Cases presentation: We report two cases of scrotal abscess following perforated appendicitis, one was 1983 and the other in 1997. The first patient developed acute left hemiscrotum two weeks following correction of a tetralogy of Fallot that was diagnosed since infancy. Scrotal drainage as well as open appendectomy and abdominal drainage were followed by uneventful recovery. Six weeks later left groin exploration revealed patent processus vaginalis which was ligated. The second patient developed redness, swelling and pain in his left hemiscrotum 10 days after open appendectomy for perforated appendicitis. Groin exploration, ligation of a PPV and scrotal drainage was made. Recent reports on the subject, review of the literature, the rarity of the complication, and the possible association with recent introduction of laparoscopic appendectomy.

Conclusion: Acute scrotal swelling is frequently a surgical emergency. Developing in the postoperative period is no exception. Symptoms and signs may be hampered by analgesia, pain, and antibiotics, usually administered in this period. Reporting these rare complications following such a common procedure, especially now a day in the era of laparoscopic surgery. Only high degree of suspicion and vigilant intervention will accomplish a safe diagnosis and treatment. The appropriate time and approach to both abscess and PPV is still controversial. Until enough case reports treatment is to be individualized.
\end{abstract}

\section{Introduction}

The scrotum develops as a part of the abdominal cavity, and the processus vaginalis remains patent $80-90 \%$ of newborns, and gradually declines to $15-37 \%$ during adulthood. In recent years several case reports of intraabdominal pathologies finding their way into the scrotum especially during peritoneal dialysis, or after placement of ventriculo-peritoneal shunt. The present cases and the literature review show that intraabdominal purulent collec- tion may find its way to the scrotum via a PPV. The sine qua non of all these cases is the PPV.

\section{Cases presentation \\ Case No I}

A 10-year-old male presented with 3 days history of abdominal pain, Anorehxia, and vomiting, admitted with the diagnosis of acute appendicitis. Abdominal examination revealed tenderness and rebound tenderness in the 
right lower quadrant of the abdomen. Temperature was $37.9^{\circ} \mathrm{C}$ and leucocytosis was $16,000 \mathrm{~mm} 3$, with left shift. At surgery acute perforated appendicitis was removed and because of the abscess cavity and difficulty in removing the appendix drainage was instituted, the peritoneal fluid was sent for culture and broad-spectrum antibiotic coverage was started. On post-operative day 5 the patient complained of swelling and redness of his left scrotal sac. There was minimal pain, US examination and Doppler US revealed a normal testis with normal blood flow, the fluid to contain debris suspected to be an abscess. Groin exploration revealed an abscess in a patent prcessus vaginalis (PPV). The PPV was ligated and the abscess was drained via the scrotum as shown in figure (1). The culture from the scrotal fluid did not grow any organism, while the peritoneal fluid grew gram negative E-coli. They were removed when the drainage stopped and the patient made a good recovery.

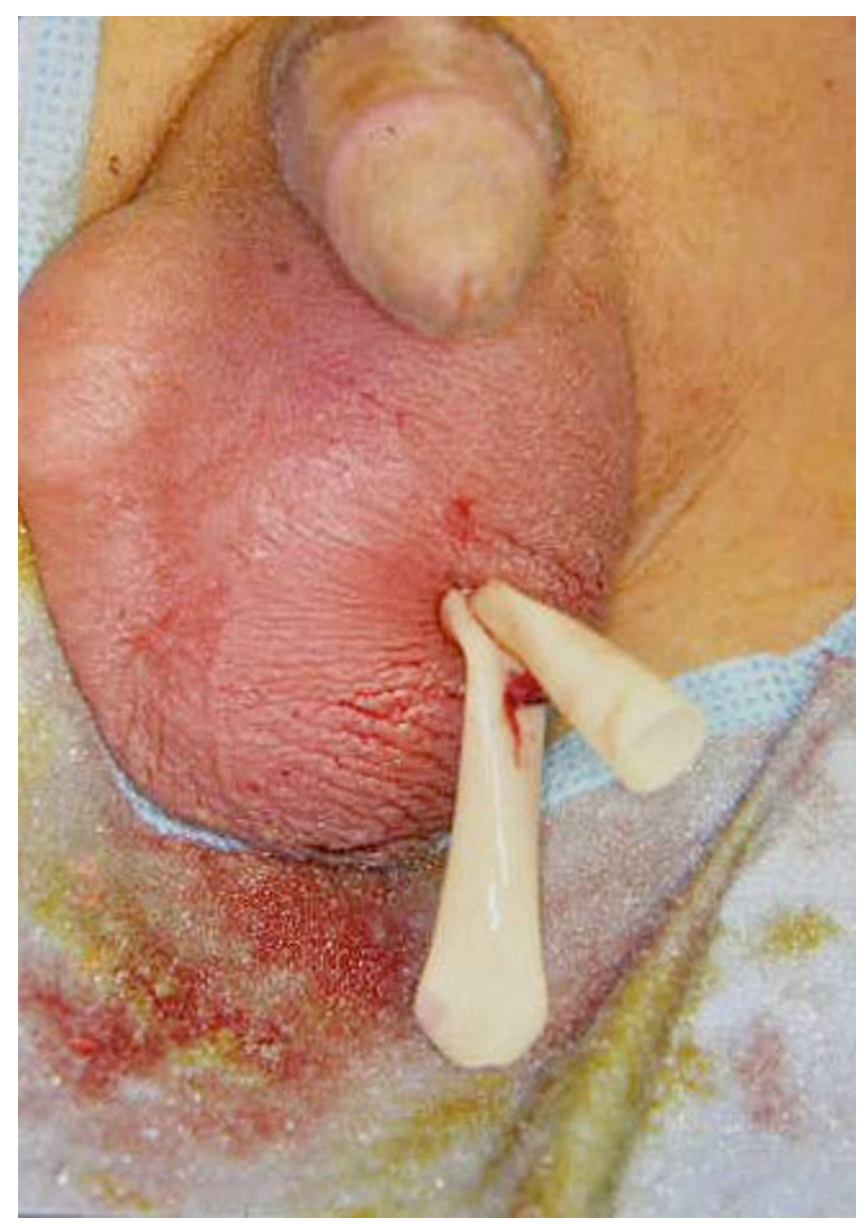

Figure I

Scrotal drainage following groin exploration.

\section{Case No 2}

A 4-year-old male complained of lower abdominal pain, fever and swelling of the left scrotal sac of two days duration. He is known to have congenital heart disease, Tetralogy of Fallot, for which he underwent surgical correction two weeks earlier. Examination revealed a swollen left scrotal sac with tenderness in the scrotum, groin and lower abdomen. Temperature was $39.2^{\circ} \mathrm{C}$, WBC 14,200 $\mathrm{mm} 3$. Diagnosis of acute scrotum was entertained and scrotal exploration was made. There was purulent scrotal fluid but the testis and epidydimis were normal. The fluid was thought to come from the abdomen as by pressing the lower abdomen the fluid was coming more. The scrotum was drained. On exploring the abdomen acute perforated pelvic appendicitis in a situs inversus situation was encountered. Appendectomy and drainage of the pelvis was performed Figure (2). Cultures from both the scrotum and peritoneum grew the same organism, Enterobacter. The drains were removed in one week. Antibiotic coverage was continued for two weeks and the patient made uneventful recovery. Six weeks later exploration of the groin revealed PPV, which was ligated.

\section{Discussion}

The relationship between the scrotum and the peritoneal cavity has long been known. Examination of the scrotum is part of the abdominal examination. Patent processus vaginalis (PPV) is thought to remain patent in 15-37\% of people beyond neonatal period. Suppuration following acute appendicitis is well known and occurs in 3-9\% following acute appendicitis [1]. Abscess formation commonly occurs in the pelvis, between intestinal loops and in the subphrenic space. Scrotum as an extension of the peritoneal cavity is very rarely considered as a site of abscess formation following appendicitis. Only recently this subject has been recognized and reported. About 30

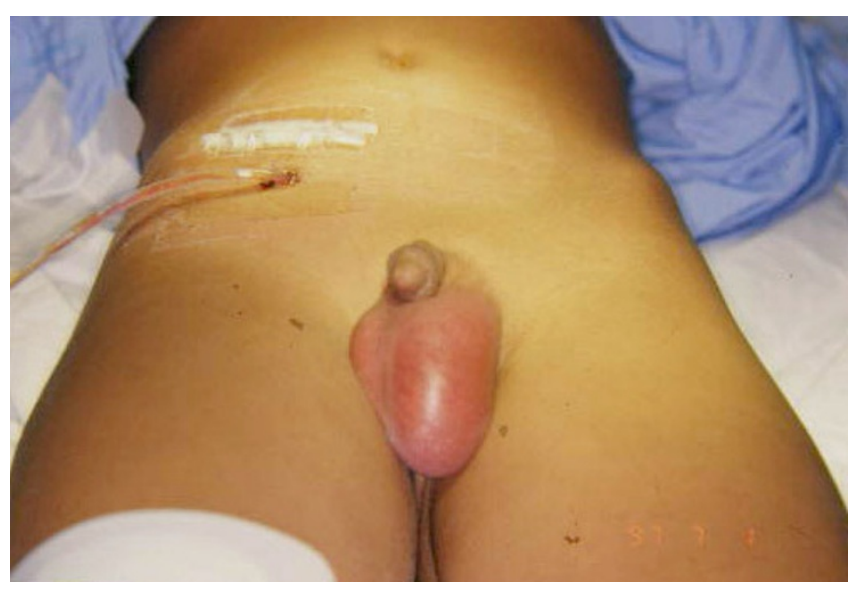

\section{Figure 2}

Pelvic drainage after appendectomy. Notice the scrotal swelling and redness of the left scrotal sac. 
pediatric cases have been reported in the literature including neonates and adolescents. There were two previous reviews [2,3]. Ours is the largest one [2-17]. We have reviewed 22 cases in which enough information was available (Table 1). Three were neonates and three were adolescents [4-8]. All were males except one female 3 years old developed an abscess in the labial fold, seven days following appendectomy for perforated appendicitis and had a patent processus vaginalis. This is the only female reported with this complication [9]. Fifteen patients had a PPV and 14 required secondary operation following their primary appendectomy procedure. These were 1-10 days postoperatively. Five patients had their primary surgery inguino-scrotal to manage both the appendectomy as well as the drainage of the scrotal suppuration [4-6,10-12]. It is postulated that laparoscopic appendectomy with insufflations of the peritoneal cavity may potentiate the patent processus vaginalis and increase the incidence of scrotal contamination by peritoneal fluid. Three cases were following laparoscopic appendectomy $[3,7,8]$. Sixteen of the reported cases and our two cases were not following laparoscopic appendectomy. Five scrotal abscesses were approached through the scrotum and three were approached inguinally. Six cases including one of ours the inguino-scrotal exploration preceded the appendectomy procedure, and five of them required no further procedure [4-6,10-12]. Absence of history of inguinal hernia or hydrocele was common to all patients including ours; the timing of abscess development was between the $1^{\text {st }}$ and the 10th day following appendectomy. Presentation was scrotal swelling and redness in all the reported cases. Pain was not the outstanding feature and if this was present it was not excruciating, as this happen in the cases of torsion of the testis, or strangulated hernia. All the patients were explored with the provisional diagnosis of inguinal hernia strangulation or incarceration. There is a reported case of testicular damage the mechanism of which is obscured [13]. In our cases the PPV were wide open at the time of abscess formation. Ligation of the PPV was performed in the first presented case during the emergency groin exploration while in the second case this was accomplished six weeks later after appendectomy.

\section{Conclusion}

Acute appendicitis with scrotal involvement in children may present with scrotal abscess or with appearance of acute scrotum mimicking acute testicular torsion or incarcerated inguinal hernia. This may precede the diagnosis of acute appendicitis or as a postoperative complication of suppurative or perforated appendicitis.

Acute scrotal swelling is frequently a surgical emergency. Developing in the post-operative period is no exception. Analgesia, and antibiotics may hamper symptoms and

Table I: a literature cases of scrotal abscess in children and adolescents as a complication of perforated appendicitis

\begin{tabular}{|c|c|c|c|c|}
\hline Author & Age (years) & Surgery (Primary) & Surgery (Secondary) & PPV \\
\hline Thakur(200I) $)^{3}$ Casel & 9 & Open appy, & Inguinal I\&D, (4) & + \\
\hline Case2 & 7 & Lap appy & Inguinal \& scrotal I\&D (I0) & + \\
\hline Dessanti $(1995)^{4}$ & 18 Days & Rt. inguinal herniotomy, appy & No further surgery & + \\
\hline Ibrahim \& Malki $(2000)^{5}$ & 22 Days & Scrotal exploration & No further surgery & - \\
\hline Martin $(2001)^{6}$ & 4 Days & Groin exploration, Open appy, herniotomy & No further surgery & + \\
\hline Lantsberg \& Mor (1997) ${ }^{7}$ & 20 & Lap appy & Scrotal I\&D (I) & - \\
\hline Kollias \& Gallery $(1996)^{8}$ & 17 & Lap appy & Scrotal I\&D (4) & - \\
\hline \multirow[t]{5}{*}{ Bengol-kologlu $(2006)^{9}$} & 3 Female & Open appy & Groin exploration (7) & + \\
\hline & 4 & Open appy & Groin exploration (5) & + \\
\hline & 7 & Open appy & Groin exploration (4) & - \\
\hline & 7 & Open appy & Groin exploration (5) & - \\
\hline & 9 & Open appy & Groin exploration (5) & - \\
\hline Sharma $(2004)^{10}$ & 6 & Rt. Inguinal, herniotomy, Open appy & No further surgery & + \\
\hline Singh $(2003) 11$ & 2 & Rt. Inguinal I\&D, Open appy & No further surgery & + \\
\hline Satchthananda $(2000)^{12}$ & 3 & Open appy & No further surgery & + \\
\hline Robertson $(1993)^{13}$ & 7 & Open appy & Scrotal exploration and orchiectomy & + \\
\hline Pal KMI(1995) 14 & 8 & Open appy & Scrotal I\&D & - \\
\hline Gan\&Sweeny $(1992)^{15}$ & 8 & Open appy & Inguinal I\&D (2) & - \\
\hline McKerrow \& Thomson(1982) 16 & 9 & Open appy & Scrotal I\&D (2) & - \\
\hline Lee Yung-chin(2003) $)^{17}$ & 19 & Open appy & $\begin{array}{l}\text { Scrotal exploration (3) Drainage of } \\
\text { retroperitoneal abscess }\end{array}$ & - \\
\hline Present cases Case I & 10 & Open appy, & Inguinal I\&D (5) & + \\
\hline Case 2 & 4 & Scrotal exploration & Herniotomy later & + \\
\hline
\end{tabular}

Total

22

Key: Appy: appendectomy, Lap: laparoscopic, PPV: patent processus vaginalis, postoperative days in parenthesis. 
signs, as these are usually administered the postoperative period. The unusual complication might follow common surgical procedures such as appendectomy, especially in laparoscopic surgery.

Only high degree of suspicion and vigilant intervention will accomplish a safe diagnosis and treatment. The appropriate time and approach to both abscess and PPV is still controversial. Until enough case reports treatment is to be individualized.

\section{Abbreviations}

PPV: patent processus vaginalis; US: Ultrasound.

\section{Consent}

Written informed consent was obtained from the patients' parents for publication of this case report and accompanying images. A copy of the written consent is available for review by the Editor-in-Chief of this journal.

\section{Competing interests}

The author declares that they have no competing interests.

\section{Authors' contributions}

This author has managed this case and prepared the manuscript.

\section{References}

I. Shmit PJ, Hiyama DT, Swisher SG, Bennion RS, Thompson JE: Analysis of risk factors of post appendectomy intraabdominal abscess. J AM Coll Surg 1994, 179:721-726.

2. Friedman SC, Sheynkin YR: acute scrotal symptoms due to perforated in children: case report and review of the literature. Pediatr Emerg Care 1995, I I: I8I-182.

3. Thakur A, Buchmiller T, Hiyama D, Shaw A, Atkinson J: Scrotal abscess following appendectomy. Pediatr Surg Int 200I, | 7:569-57|.

4. Dessanti A, Porcu A, Scanu A, Dettori G: Neonatal acute appendicitis in an inguinal hernia. Pediatr Surg Int 1995, 10:561-562.

5. Ibrahim AHM, Al-Malki TA: scrotal appendicitis mimicking acute testicular torsion in a neonate. Ann Saudi Med 2000 20:55-56.

6. Martins JL, Peterlini FL, Martins ECS: Neonatal acute appendicitis: A strangulated appendix in an incarcerated inguinal hernia. Pediatr Surg Int 2001:644-645.

7. Lantsberg L, Mor J, Levy I, Khoda J: Infected hydrocele laparoscopic appendectomy: Case report. Surg Laparosc Endosc 1997, 7:262.

8. Kollias ], Gallery RM: Left scrotal abscess complicating laparoscopic appendectomy. Aust N Z J Surg 1996, 66:568-569.

9. Bengol-kologlu M, Fedakar $M$, Yagmurlu $A$, dindar $H$, gokcora $H$ : An exceptional complication following appendectomy: acute inguinal and scrotal suppuration. Int, Urol Nephrol 2006, 38:663-665.

10. Sharma SB, Gupta V: acute appendicitis presenting as acute hemiscrotum in a boy. Indian J Gastroenterol 2004, 23(4): I50-I 51 .

II. Singh S, Adiverkar P, Karmarkar S: acute scrotum in children: a rare presentation of acute non-perforated appendicitis $\mathrm{Pal}$ KMI, ( 1 995) Scrotal suppuratioafter appendicitis. I ClinPrac 2003, 49:279-280.

12. Satchithananda k, Beese RC, Sidhu PS: acute appendicitis presenting with a testicular mass: ultrasound appearance. $\mathrm{Br} J$ radiol 2000, 73:780-782

13. Robertson FM, Olsen SB, Jackson MR, Rochon RB: Inguinal-scrotal suppuration following treatment of perforated appendicitis. J Pediatr Surg 1993, 28:267-268.
14. Pal KMI: Scrotal suppuration after appendicitis. J ClinPrac 1995 , 49:279-280.

I5. Gan BS, Sweeny JP: An unusual complication of appendectomy. J Pediatr Surg 1992, 29:1622.

16. McKerrow WS, Thomson HJ: unusual complication of perforated appendix. $\mathrm{Br}$ Med J 1982, 284: 1442

17. Lee Yung-chin, Wu Wen-Jeng, Huang Shu-Pin, Tsai hsiu-nan, et al.: scrotal abscess originating from appendicitis: a case report Kaohsiung. J Med Sci 2003, I 9(5):242-245.
Publish with Bio Med Central and every scientist can read your work free of charge

"BioMed Central will be the most significant development for disseminating the results of biomedical research in our lifetime. "

Sir Paul Nurse, Cancer Research UK

Your research papers will be:

- available free of charge to the entire biomedical community

- peer reviewed and published immediately upon acceptance

- cited in PubMed and archived on PubMed Central

- yours - you keep the copyright
BioMedcentral 